\title{
Centromeric heterochromation exchange by an autosomal reciprocal $1 / 16$ translocation in the pig (Sus scrofa domestica)
}

\author{
M. FÖRSTER \\ Institute of Animal Genetics, Technical University Munich, \\ D-8050 Freising-Weihenstephan, West Germany
}

\begin{abstract}
Summary
The base pair specific DNA binding fluorochromes, chromomycin $A_{3}$ (CMA), distamycin A (DA) and 4'-6-diamidino-2-phenylindole (DAPi), can be used for differentiation of the centromeric regions in pig chromosomes. All bi-armed chromosomes are strongly stained in the centromere by the G-C specific chromomycin $\mathbf{A}_{3}$. The A-T specific DA-DAPi staining procedure shows brilliant fluorescence on the centromeres of all one-armed chromosomes. In the pig, chromosome 1 is a large submetacentric and chromosome 16 a small acrocentric chromosome. A centromeric heterochromatin exchange can be demonstrated in a reciprocal $1 / 16$ translocation in the pig. The A-T rich centromeric heterochromatin of the chromosome 16 is translocated to the large arm of chromosome 1 while the G-C rich centromere, together with the short arm of chromosome 1 , is attached to the chromosome 16 , forming a new medium sized metacentric chromosome with a $\mathrm{G}-\mathrm{C}$ rich centromere. The sequential CMA/DA/DAPi stain demonstrates well the balance of this reciprocal translocation. This stain permits demonstration of heterochromatin exchange and total conservation of the centromeric regions. In contrast, DAPi-stain gives no information about the exact break and reunion situations in this case.
\end{abstract}

\section{Introduction}

In German Landrace pigs a new balanced autosomal reciprocal translocation was reported (Förster et al., 1981). The short arm of chromosome 1 was broken near or in the centromere and attached to the centromere of the acrocentric chromosome 16. In the pig, centromeric heterochromatin is different between bi-armed and uni-armed chromosomes. JORGENSEN et al. (1978) reported a strong affinity of the G-C specific fluorochromes olivomycin, chromomycin $\mathbf{A}_{3}$ and mithramycin to all centromeres of the bi-armed chromosomes in pigs. SCHNEDL et al. (1981) demonstrated a strong affinity of A-T specific stains to the centromeric heterochromatin of the one-armed acrocentric chromosomes in pig. The CMA/DA/DAPi sequential triple stain of SCHWEITZER (1980) allows the identification of the involved G-C specific and DA-DAPi positive heterochromatic material of the chromosomes 1 and 16 . 


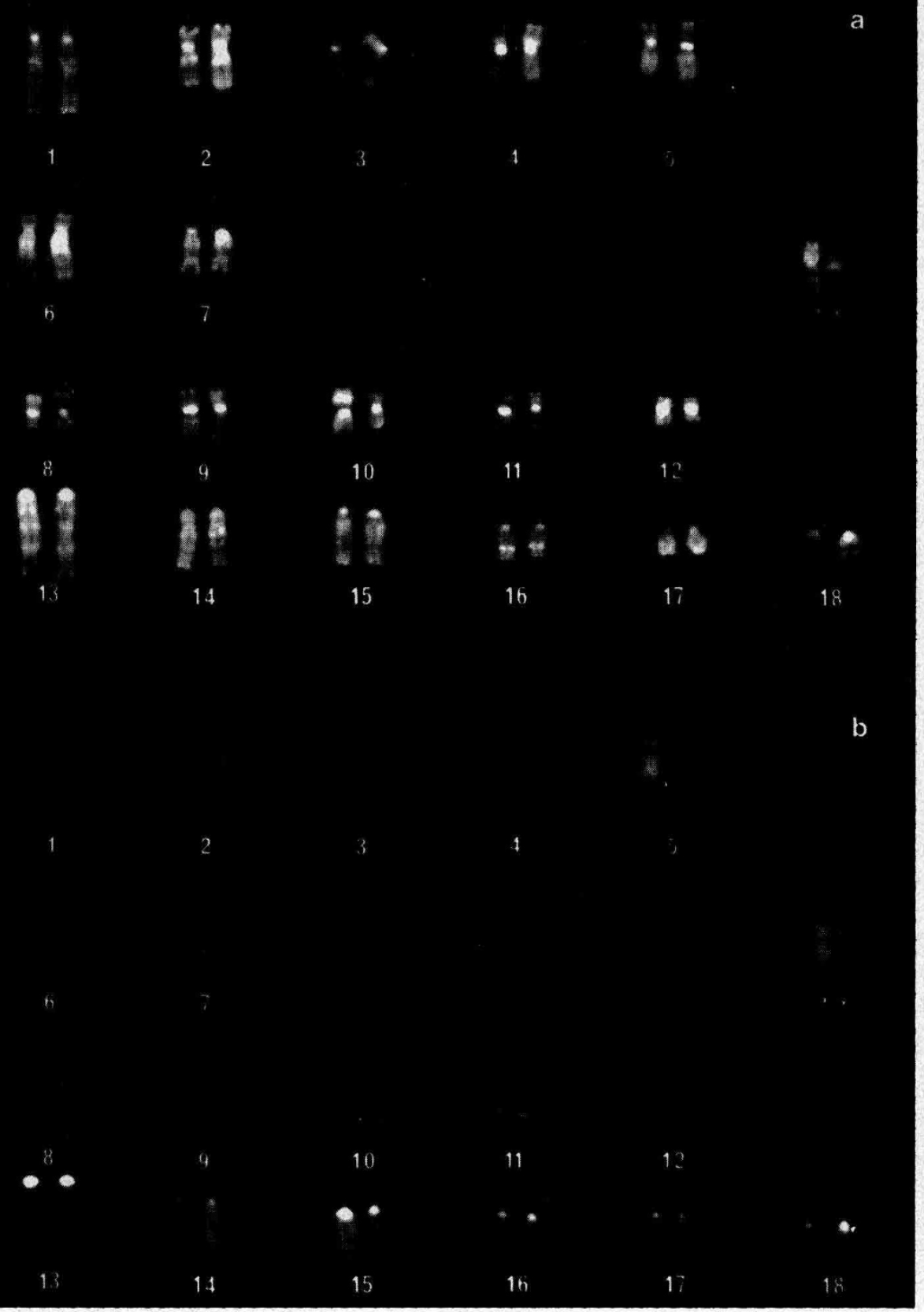

FIG. 1

Karyotypes from one metaphase after chromomycin As-distamycin A-DAPi triple stain

a) chromomycin As-R-bands,

b) distamycin A/DAPi stain.

Caryotypes d'une métaphase après triple coloration chromomycin, As distamycine, A-DAPi a) bandes en $A_{s}-R$,

b) coloration distamycine A/DAPi. 


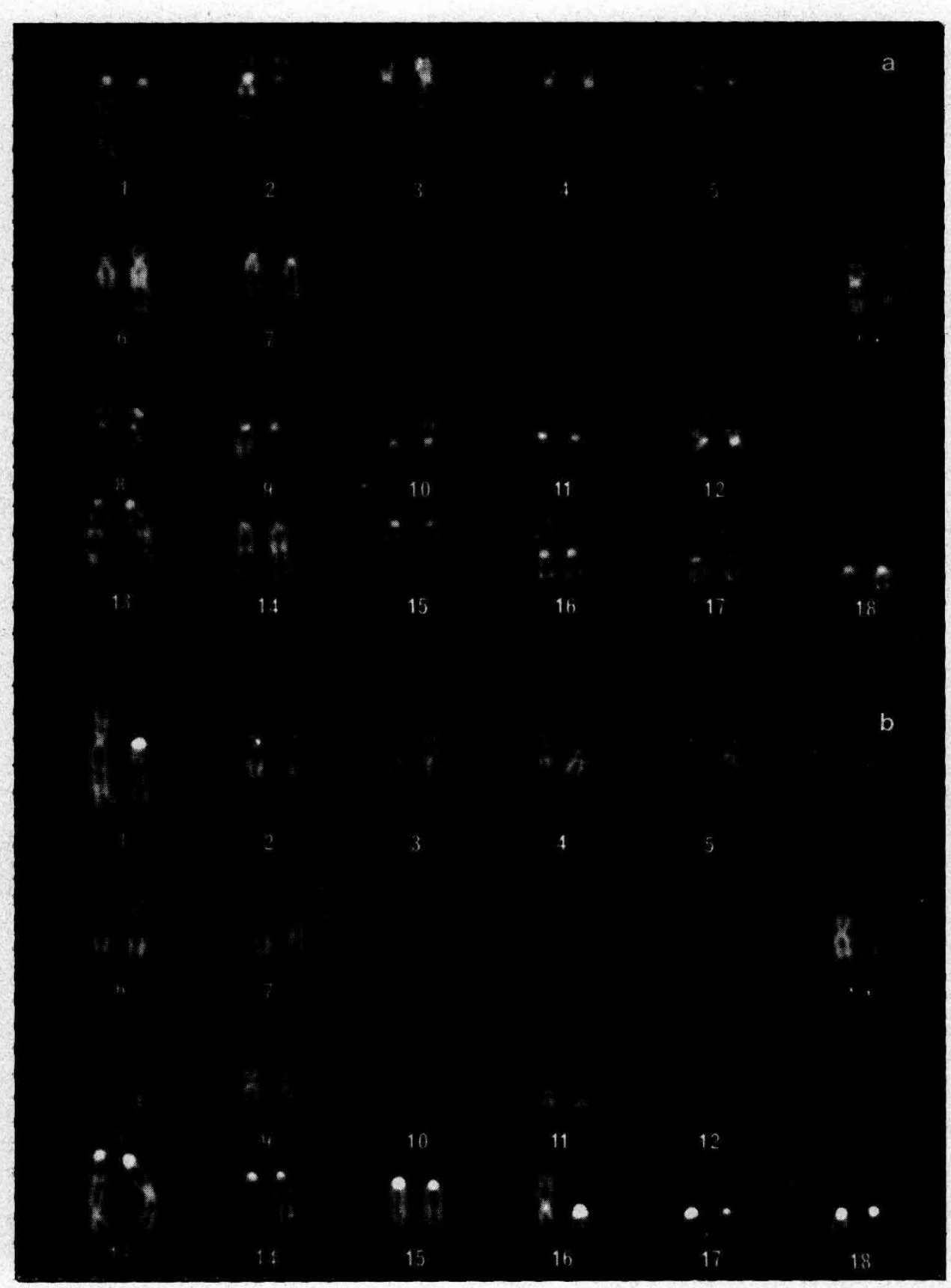

FIG. 2

The tri-stained karyotypes of one metaphase with the $1 / 16$ translocation a) chromomycin As-banding,

b) $D A-D A P i$ positive heterochromatin on all onearmed chromosomes. The large arm from chromosome 1 with an DA-DAPi positive centromere. The new $1 / 16$ chromosome without an $D A-D A P i$ positive centromer.

Caryotypes tri-colorié d'une métaphase avec la translocation $1 / 16$

a) bandes chromomycine $A$,

b) hétérochromatine $D A-D A P i$ positif sur tous les chromosomes acrocentriques. Le bras long du chromosome 1 avec un centromère $D A-D A P i$ positif. Le nouveau chromosome $1 / 16$ sans centromère DA-DAPi positif. 


\section{Material and methods}

\section{Chromosome preparation}

Porcine chromosomes were prepared from pokeweed stimulated short-term peripheral blood cultures by the routine $\mathrm{KCl}$-hypotonic treatment and methanol-acetic acid fixations.

\section{Chromosome banding techniques}

A sharper DAPI band pattern was obtained by an actinomycin D (AMD) counterstaining. The slides were stained for $20 \mathrm{~min}$ by and AMD-solution $(0.25 \mathrm{mg} / \mathrm{ml}$ aq dest.), rinsed briefly by Mc Illvain's citric acid/ $\mathrm{Na}_{2} \mathrm{HPO}_{4}$ buffer at $\mathrm{pH} 7.0$ and then stained for $20 \mathrm{~min}$ by DAPi $(0.6 \mu \mathrm{g} / \mathrm{ml} \mathrm{aq} \mathrm{dest.).} \mathrm{The} \mathrm{simultaneous} \mathrm{R}$ - and DA-DAPi bands were stained by a method described previously by ScHWEITZER (1980). Chromomycin $\mathrm{A}_{3}(0.5 \mathrm{mg} / \mathrm{ml})$ was dissolved in Mc Illvains buffer at $\mathrm{pH} 7.0$ containing $5 \mathrm{mM} \mathrm{Mg} \mathrm{Cl} \mathrm{m}_{2}$. The slides were stained for $30 \mathrm{~min}$ with CMA, washed by buffer, stained with distamycin $A(0.1 \mathrm{mg} / \mathrm{ml}$ aq dest $)$, rinsed again and stained with DAPi $(0.6 \mathrm{mg} / \mathrm{ml}$ aq dest). Finally, the rinsed and briefly dried slides were mounted in an mixture of one part glycerol and one part Mc Illvains pH 7 buffer.

\section{Chromosome microscopy}

Fluorescence was observed by a Leitz Orthoplan. AMD-DAPi and CMA $_{3}$ fluorescence were photographed with the $\mathrm{H} 2$ or E3 filter and the DA-DAPi pattern with filter A. All photos were taken on Kodak technical-pan film, and processed with a D-19 developer.

\section{Results}

A normal banding pattern like DAPi or AMD-DAPi shows only the translocation of the short arm of the chromosome 1 to the chromosome 16 (fig. 3). No information about the role of the centromeric heterochromatin in this translocation case is available by such a staining process. The involment of a G-C rich centromere from chromosome 1 and DA-DAPi positive centromeric heterochromatin from the chromosome 16 can be shown by the CMA/DA/DAPi triple staining (fig. 1). The metaphase was photographed first for the G-C specific chromomycin $A_{3}$-R-band with the E3 or $\mathrm{H} 2$ filter and then after changing the filter from E3 to A, for the specific DA-DAPi pattern (SCHNEDL et al., 1981). In this translocation the usual staining methods show only breakpoints near or in the centromere regions of the chromosome 1 and 16. Therefore no differentiation is possible between a centromere-fission-fusion procedure, forming a dicentric chromosome of minute centromeric fragments, or a reciprocal translocation event. However, the base pair specific CMA/DA/DAPi tristain demonstrates a centromeric heterochromatin exchange (fig. 2). The DA-DAPI positive centromere from chromosome 16 is translocated proximal to the large arm of chromosome 1 , while the G-C rich centromere, together with the whole short arm 


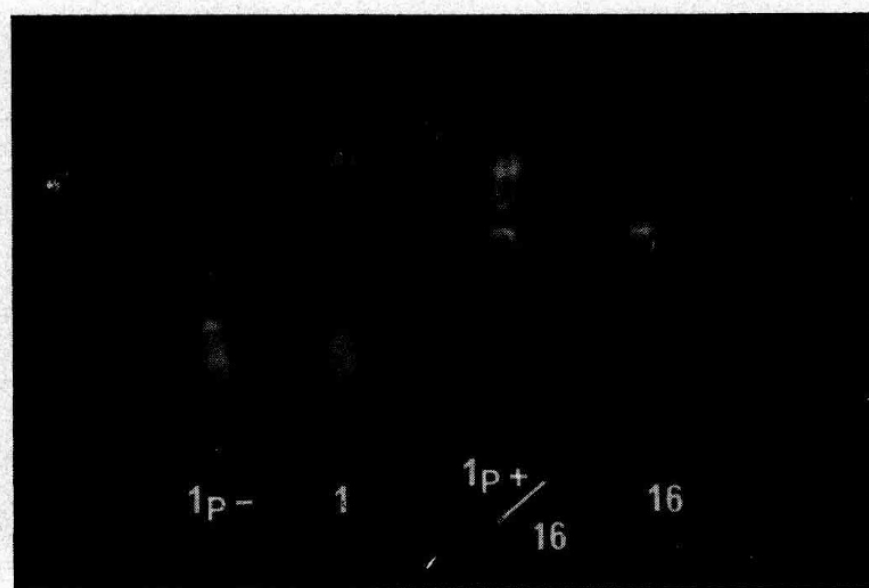

Fig. 3

Detailed scheme of the translocation stained by an actinomycin D.DAPi banding methode.

Arrangement détaillé de la translocation coloré par la méthode de la bande actinomycine DA-DAPi.

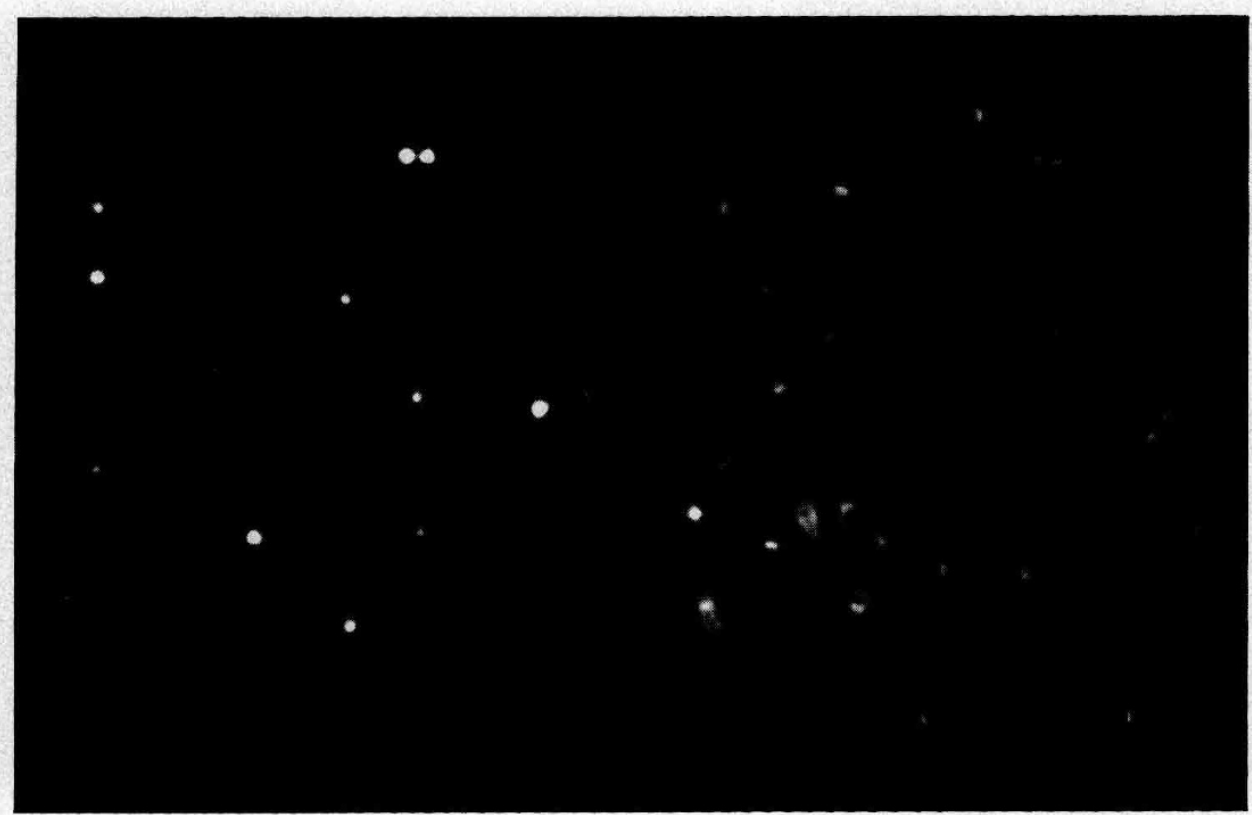

Fig. 4

A metaphase simultaneous stained for CMA and DA-DAPi showing no centromeric fragment in this translocation case.

Une métaphase colorée simultanément par CMA et DA-DAPi qui ne montre aucun fragment centromérique dans ce cas de translocation. 
of number 1 , is attached proximal to chromosome 1 . It seems, that only DA-DAPI positive centromeric heterochromatin from chromosome 16 and only the short arm and the G-C rich centromere but no material from the large arm of chromosome 1, are involved. The metaphase in figure 4 demonstrates the conservation of all centromeric material involved in the $1 / 16$ translocation and the absence of centromeric fragments or dicentric chromosomes.

\title{
IV. Discussion
}

G-C and DA-DAPI positive heterochromatin characterize the different centromeric regions in pig chromosomes. A reciprocal translocation near to centromeres of two chromosomes with different centromeric heterochromatin types can elucidate more precisly the translocation mechanism in that specific case, whereas a traditional Q- or G-like band pattern does not. For example, Actinomycin D/DAPI-stain does not clarify the break point. Such a staining method can lead to misinterpretation in assuming that the short arm of chromosome 1 is broken up and attached to the centromere of the acrocentric chromosome 16 like a centromere-fission-fusion process. This procedure can not answer the question about the remaining and translocated centromeric regions of both involved chromosomes. If a centromere-fission-fusionevent had occured in this translocation, then a new dicentric chromosome would arise, or, in the case of a monocentric, form a minute fragment in which heterochromatic material would appear.

However, the simultaneous R-band-DA/DAPI triple stain demonstrated very clearly the formation of a new middle sized metacentric chromosome (1/16), with a G-C heterochromatic centromere. The DA-DAPI positive centromeric heterochromatin from the chromosome 16 is translocated to the large arm of the chromosome 1 . It seems that no further chromosomal material was translocated from chromosome 16 to 1 , as far as it was recognizable by the AMD-DAPI stain. On the other side, the short arm of chromosome 1 and the G-C rich centromere, but no other chromosome segments, are attached to the remaining centromerless chromosome 16.

Therefore, this specific translocation event represents the classical type of a balanced, autosomal reciprocal translocation, forming two morphologically new chromosomes, each with an active single centromere.

Received for publication in december 1981.

\author{
Résumé \\ L'échange d'hétérochromatine centromérique \\ dans une translocation réciproque autosomique chez le porc \\ (Sus scrofa domestica)
}

Les fluorochromes qui ont la propriété de se lier spécifiquement avec les deux paires de bases du DNA, la chromomycine $A_{3}$ (CMA), la distamycine A (DA) et la 4'-6-diamidino2-phenylindole (DAPi), peuvent être employés pour différencier les régions centromériques des chromosomes du porc. La shromomycine $A_{3}$ se lie spécifiquement avec les bases G-C, 
tandis que la distamycine A et la 4'-6-diamidino-2-phenylindole avec les bases AT. Tous les chromosomes méta-submétacentriques ont les centromères intensément colorés par CMA. La coloration avec DA-DAPi permet d'obtenir une fluorescence brillante dans les centromères de tous les chromosomes acrocentriques.

Chez le porc, le chromosome 1 est un grand submétacentrique et le chromosome 16 un petit acrocentrique. On a mis en évidence un échange d'hétérochromatine centromérique dans la translocation réciproque $1 / 16$ chez le porc. L'hétérochromatine centromérique riche en A-T du chromosome 16 est retrouvée sur le bras long du chromosome 1.

La partie comprenant le centromère riche en G-C et le bras court du chromosome 1 est attachée au chromosome 16 et forme, ainsi, un nouveau chromosome métacentrique de taille moyenne porteur d'un centromère riche en G-C. Le marquage séquentiel CMA/DA/ DAPi montre bien que cette translocation réciproque est équilibrée. Cette coloration a permis de montrer l'échange d'hétérochromatine et la conservation totale des régions centromériques. Cependant, dans ce cas, le marquage avec DAPi n'apporte pas d'informations sur le lieu exact des cassures et des réunions des segments chromosomiques.

\section{References}

FörSter M., Willeke H., RiChter L., 1981. Eine autosomale, reziproke 1/16 Translokation bei Deutschen Landrasse Schweinen. Zuchthygiene, 16, 54-57.

Jergensen K.F., VAN DE SANDE I.H., Lin C.C., 1978. The use of base pair specific DNA binding agents as affinity labels for the s'udy of mammalian chromosomes. Chromosoma (Berl.), 68, 287-302.

Schnedl W., Abraham R., Dann O., Geber G., Schweitzer D., 1981. Preferential fluorescent staining of heterochromatic regions in human chromoscmes no. 9,15 and the $y$ by «D 278/170». Human Genet. (in press).

SChnedl W., Abraham R., Förster M., Schweitzer D., 1981. Differertial fluorescent staining of procine heterochromatin by chromomycin $A_{3}$ /distamycin A/DAPi and D 287/170. Cytogenet. Cell Genet. (in press).

SCHWEITZER D., 1980. Simultaneous fluorescent staining of $\mathbf{R}$ bands and specific heterochromatic regions (DA-DAPi bands) in human chromosomes. Cytogenet. Cell Genet., 27, 190-193. 